University of Nebraska - Lincoln

DigitalCommons@University of Nebraska - Lincoln

Chemical and Biomolecular Engineering -- All

Faculty Papers

Chemical and Biomolecular Engineering,

Department of

2019

\title{
Comparative kinetic modeling of growth and molecular hydrogen overproduction by engineered strains of Thermotoga maritima
}

\author{
Raghuveer Singh \\ University of Nebraska-Lincoln, raghuveer@huskers.unl.edu \\ Rahul Tevatia \\ University of Nebraska-Lincoln, rahultevatia_83@yahoo.co.in \\ Derrick White \\ University of Nebraska-Lincoln \\ Yasar Demirel \\ University of Nebraska-Lincoln, ydemirel2@unl.edu \\ Paul H. Blum \\ University of Nebraska - Lincoln, pblum1@unl.edu
}

Follow this and additional works at: https://digitalcommons.unl.edu/chemengall

Part of the Biomedical Engineering and Bioengineering Commons, and the Catalysis and Reaction Engineering Commons

Singh, Raghuveer; Tevatia, Rahul; White, Derrick; Demirel, Yasar; and Blum, Paul H., "Comparative kinetic modeling of growth and molecular hydrogen overproduction by engineered strains of Thermotoga maritima " (2019). Chemical and Biomolecular Engineering -- All Faculty Papers. 88.

https://digitalcommons.unl.edu/chemengall/88

This Article is brought to you for free and open access by the Chemical and Biomolecular Engineering, Department of at DigitalCommons@University of Nebraska - Lincoln. It has been accepted for inclusion in Chemical and Biomolecular Engineering -- All Faculty Papers by an authorized administrator of DigitalCommons@University of Nebraska - Lincoln. 


\title{
Comparative kinetic modeling of growth and molecular hydrogen overproduction by engineered strains of Thermotoga maritima
}

\author{
Raghuveer Singh, ${ }^{1}$ Rahul Tevatia, ${ }^{2}$ Derrick White, ${ }^{1}$ \\ Yaşar Demirel, ${ }^{2}$ Paul Blum ${ }^{1}$ \\ 1 Beadle Center for Genetics, University of Nebraska-Lincoln, 68588, USA \\ 2 Department of Chemical and Biomolecular Engineering, \\ University of Nebraska-Lincoln, 68588, USA \\ Corresponding authors - R. Singh \& P. Blum; E234 Beadle Center for Genetics, \\ School of Biological Sciences, University of Nebraska-Lincoln, Lincoln NE 68588- 0666, USA; \\ email raghuveer@huskers.unl.edu ; pblum1@unl.edu
}

\begin{abstract}
Thermotoga maritima is an anaerobic hyperthermophilic bacterium known for its high amounts of hydrogen $\left(\mathrm{H}_{2}\right)$ production. In the current study, the kinetic modeling was applied on the engineered strains of T. maritima that surpassed the natural $\mathrm{H}_{2}$ production limit. The study generated a kinetic model explaining $\mathrm{H}_{2}$ overproduction and predicted a continuous fermentation system. A Leudking-Piret equationbased model predicted that $\mathrm{H}_{2}$ production by Tma200 ( $0.217 \mathrm{~mol}-\mathrm{H}_{2} \mathrm{~g}^{-1}$-biomass) and Tma100 (0.147 mol- $\mathrm{H}_{2} \mathrm{~g}^{-1}$-biomass) were higher than wild type $\left(0.096 \mathrm{~mol}-\mathrm{H}_{2}\right.$ $\mathrm{g}^{-1}$-biomass) with reduced rates of maltose utilization. Sensitivity analysis confirmed satisfactory fitting of the experimental data. The slow growth rates of Tma200 (0.550 $\left.\mathrm{h}^{-1}\right)$ and Tma100 $\left(0.495 \mathrm{~h}^{-1}\right)$ are compared with the wild type $\left(0.663 \mathrm{~h}^{-1}\right)$. A higher

Published in International journal of Hydrogen Energy 44 (2019), pp 7125-7136

doi 10.1016/j.ijhydene.2019.01.124

Copyright $(2019$ Hydrogen Energy Publications LLC; published by Elsevier Ltd. Used by permission.

Submitted 5 September 2018; revised 7 January 2019; accepted 10 January 2019; published 11 February 2019.
\end{abstract}


maintenance energy along with growth and non-growth $\mathrm{H}_{2}$ coefficients corroborate the higher $\mathrm{H}_{2}$ productivity of the engineered strains. The modeled data established a continuous fermentation system for the sustainable $\mathrm{H}_{2}$ production.

Keywords: Bio hydrogen beyond Thauer limit, Biofuel, Dark fermentation, Kinetic modeling, Continuous stirred tank reactor, Natural gas phase out

\section{Introduction}

The need for energy is increasing across the world and this need is anticipated to increase for the next twenty years. The U.S. Energy Information Administration (EIA) based on the "International Energy Outlook 2013 and 2018 project" indicated that the world's energy consumption will grow by 56\% between 2010 and 2040, from 524 quadrillion Btu to 820 quadrillion Btu accompanied by a sudden surge in electricity use after 2020. Among various sources of energy, molecular hydrogen $\left(\mathrm{H}_{2}\right)$ offers a promising clean fuel because of its higher energy content per unit weight ( $142 \mathrm{~kJ} \mathrm{~g}^{-1}$ or $61,000 \mathrm{Btu} \mathrm{lb}^{-1}$ ) relative to alternatives [1]. Hydrogen is an energy carrier and energy from hydrogen can be released either by direct combustion which generates water or by conversion to electricity via a fuel cell to power electric vehicles [2-4]. However, the majority of $\mathrm{H}_{2}$ is derived from nonrenewable sources such as natural gas and coal that threaten environmental quality because of the associated production of $\mathrm{CO}_{2}$, a green-house gas [5]. In response to this issue, the German Energiewende projects to supplant fossil fuel with renewable energy by 2050 [6]. Additionally, several countries have proposed to abandon the use of vehicles powered by fossil fuels [7] and the US Department of Energy (DOE) plans to phase out the use of natural gas by 2050 [8]. Renewable and affordable $\mathrm{H}_{2}$ production may help mitigate the adverse effects of fossil fuels. When fossil fuels are phased out, continuation of the established hydrogen market would demand a technology for renewable hydrogen production technology.

Biological methods for $\mathrm{H}_{2}$ production could provide a renewable energy source though low productivity has remained an obstacle for sustainable production. The stoichiometric conversion of organic acids to $\mathrm{H}_{2}$ during photofermentation by photoautotrophic microbes employ light as an energy source for $\mathrm{H}_{2}$ production, however the key enzyme, nitrogenase, produces $\mathrm{H}_{2}$ only in response to nitrogen deprivation, an extreme physiologic stress. Therefore, this bioprocess has 
limitations preventing its application at the industrial scale [9]. A sustainable and biologically stress-free method for renewable $\mathrm{H}_{2}$ production uses microbial fermentation. This is an anaerobic process operating without the need for oxygen or light sometimes called dark fermentation that yields $\mathrm{H}_{2}$ as a co-product from the partial oxidation of sugar [10]. Microbial $\mathrm{H}_{2}$ production through dark fermentation is energetically favored as it does not require external energy $[11,12]$ and is compatible with the growing availability of renewable sugar sources obtained from lignocellulosic biomass feedstocks. Among all $\mathrm{H}_{2}$ producing bacteria, hyperthermophiles are the most promising biological choice $[1,13,14]$ because high cultivation temperature favors the energetics of $\mathrm{H}_{2}$ production, promotes solubilization and hydrolysis of complex substrates to fermentable sugars, and inhibits growth of $\mathrm{H}_{2}$ consuming contaminating microorganisms naturally resident in feedstocks. However, in closed batch culture systems accumulation of $\mathrm{H}_{2}$ inhibits cell growth [15]. This can be alleviated by continuous stripping of $\mathrm{H}_{2}$ using molecular nitrogen $\left(\mathrm{N}_{2}\right)$ influx or the use of an in-line vacuum of the fermentation head-space resulting in improved $\mathrm{H}_{2}$ production and better growth $[16,17]$. Therefore, bench-scale bioreactor studies have become crucial since they can be used to address endproduct growth inhibition and to enable prediction of process parameters required for scale up [18].

Thermotoga maritima is a hyperthermophilic anaerobic bacterium that grows optimally at $80^{\circ} \mathrm{C}$ and excretes $\mathrm{H}_{2}$ to levels that approach the biological/physiological limit of hydrogen production $[14,19,20]$ using simple and complex carbohydrates [21]. Natural strains of $T$. maritima employs the pathways of Embden-Meyerhof-Parnas (85\% relative contribution) and the Entner-Doudorof (15\% relative contribution) $[13,14,22]$ to produce $\mathrm{H}_{2}, \mathrm{CO}_{2}$ and organic acids (lactate, acetate) from sugar oxidation (Fig. S2). Four moles of $\mathrm{H}_{2}$ are produced per mole of glucose by a bifurcating hydrogenase that accepts electrons and protons simultaneously from reduced NADH and ferrodoxin [23]. Organic acids including acetate and lactate are also produced in proportional amounts. Lactic acid production is dependent on culturing conditions as batch cultivation has been reported to shift the metabolism towards lactic acid production under a high partial pressure of $\mathrm{H}_{2}$ [24] but not in its absence [25].

Kinetic modeling using various approaches [10] has been applied to biological $\mathrm{H}_{2}$ formation to optimize $\mathrm{H}_{2}$ production and to achieve 
process scale up [26]. However, the Thauer limit (Thauer et al., 1977), the thermodynamic limit of $4 \mathrm{~mol} \mathrm{ofH}_{2}$ per mole of hexose imposed by cell-based energetic constraints, is the major obstacle limiting economic industrial production of $\mathrm{H}_{2}$ through dark fermentation [27]. Overcoming this limit by improving the conversion of sugar to $\mathrm{H}_{2}$ could lead to a superior $\mathrm{H}_{2}$ production system and a new technology that may supersede fossil fuel-based $\mathrm{H}_{2}$ production. Previously, genetically engineered cell lines of $T$. maritima were developed using a method called transient gene inactivation that were called Tma100 and Tma200 $[25,28]$. These cell lines were found to over-produce $\mathrm{H}_{2}$ relative to the natural (wild type) lineage and thereby surpassed the $\mathrm{H}_{2}$ productivity previously proposed for a fermentative bacterium. While applications of these strains are of some interest, kinetic parameters must be obtained first by utilizing modeling and bioreactor-based studies.

Here kinetic modeling was performed to predict the maximum $\mathrm{H}_{2}$ molar yields and growth of the evolved T. maritima cell lines using maltose as a fermentable substrate. The kinetic modeling can be employed for modeling hydrogen production from engineered strains overproducing hydrogen and may provide a basis for large scale and continuous fermentation processes.

\section{Materials and methods}

\section{Strains and bioreactor set up}

Thermotoga maritima MSB8 (wild type, type, strain) and excess $\mathrm{H}_{2}$ producing strains (Tma100 and Tma200) [25], used in this study, were cultivated in $3 \mathrm{~L}$ double-jacketed glass bioreactors (Applikon, MA) at $80^{\circ} \mathrm{C}$ containing $1.5 \mathrm{~L}$ complex medium [29]. Bioreactor-based cultivation was employed to overcome growth inhibition caused by $\mathrm{H}_{2}$ accumulation through headspace exchange. Prior to inoculation, the cultivation medium was reduced by addition of $0.1 \%\left(\mathrm{wv}^{-1}\right) \mathrm{Na}_{2} \mathrm{~S}$ followed by supplementation with maltose at a final concentration of $15 \mathrm{mM}(\mathrm{mM})$. As shown in Fig. 1, anaerobic conditions in the bioreactor were maintained by continuous sparging of $\mathrm{N}_{2}$ at $15 \mathrm{~mL} \mathrm{~min}{ }^{-1}$. The medium was stirred at $200 \mathrm{rpm}$ using two axial impellers. Temperature, $\mathrm{pH}$ and dissolved oxygen were monitored using immersed sensors and a $\mathrm{pH}$ of 7.0 was maintained by metered addition of $\mathrm{HCl}$ 


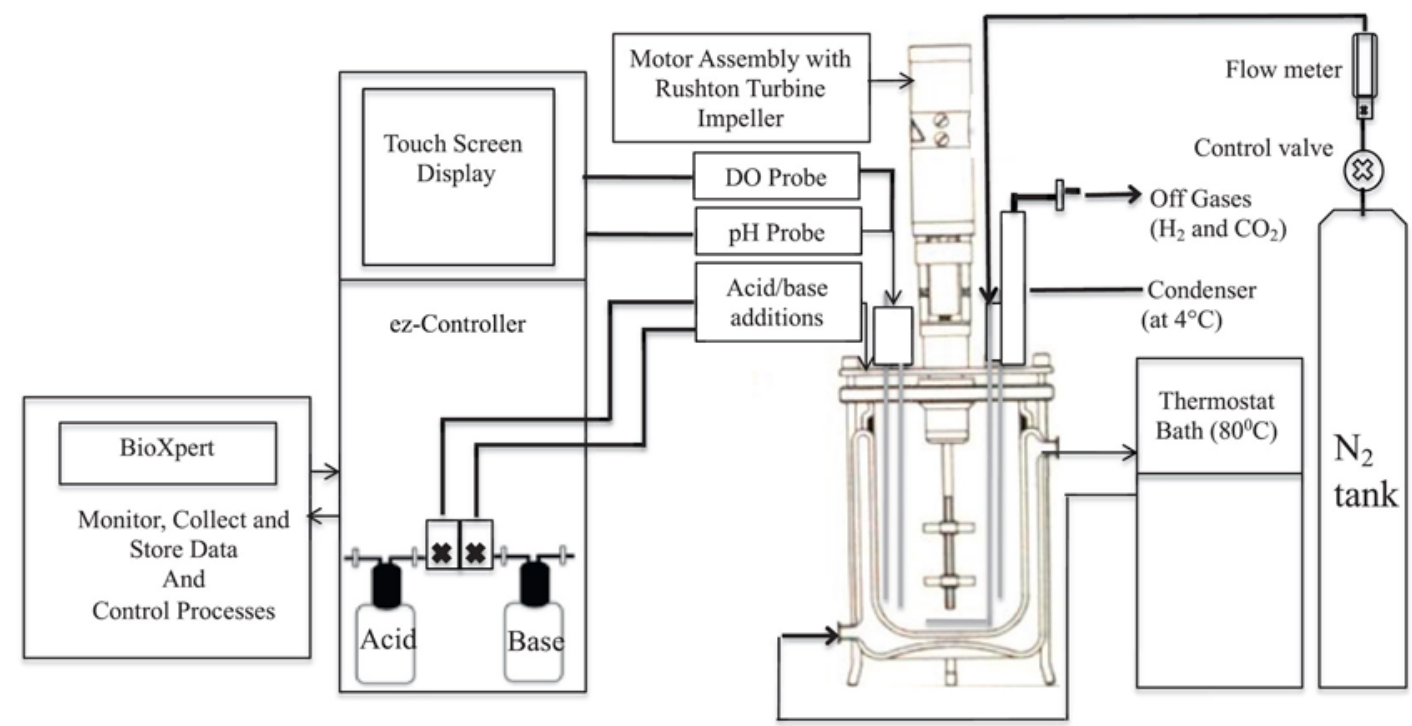

Fig. 1. Schematic representation of a $3 \mathrm{~L}$ anaerobic fermenter set-up for wild type, Tma100 and Tma200 with associated control units and data acquisition system.

or $\mathrm{NaOH}$ as needed using peristaltic pumps. To minimize water loss, the water vapor present in the outgassing headspace was returned to the vessel by condensation using a chilled water supply. Samples were removed periodically using an external syringe to determine culture cell density determined as the optical density $\left(\mathrm{OD}_{600}\right)$, and subsequent organic acid and residual maltose analysis. For $\mathrm{H}_{2}$ sampling, a gas tight syringe (Hamilton) was used to withdraw samples from a rubber septum located on the head plate of the bioreactor.

\section{Analysis of metabolites}

Analysis of headspace gas was performed by injecting $500 \mathrm{~mL}$ volumes into a gas chromatograph (GC 400 Series, GOWMAC, PA) fitted with a thermal conductivity detector. $\mathrm{N}_{2}$ gas was used as a carrier and separation of the sample gas was carried out at $70^{\circ} \mathrm{C}$ using a molecular sieve column (GOWMAC). For headspace $\mathrm{CO}_{2}$ analysis, a Varian (430) GC equipped with an Alltech Porapak C-5000 column was used. Helium was used as the carrier gas, and column temperature was maintained at $65^{\circ} \mathrm{C}$ to separate $\mathrm{CO}_{2}$. Calibration curves were obtained by injecting various volumes of pure $\mathrm{H}_{2}$ and $\mathrm{CO}_{2}$ and the amount of $\mathrm{H}_{2}$ and $\mathrm{CO}_{2}$ in the headspace was estimated by comparison to these 
values. The ideal gas law was used to calculate the amount of $\mathrm{H}_{2}$ and $\mathrm{CO}_{2}$ that was produced at standard temperature and pressure (STP). Organic acids and maltose concentrations were determined in culture supernatants by HPLC with comparison to standards. Prior to injection, samples were clarified by centrifugation at $10,000 \times \mathrm{g}$ rpm for 10 min and then filtered (AcroDisc, $0.45 \mu \mathrm{M})$. Samples $(1 \mu \mathrm{L})$ were analyzed using an Agilent $1200 \mathrm{HPLC}$ system and an automated sampler equipped with a Refractive Index Detector and a Hi-Plex $\mathrm{H}$ column (ChromTech) operated at $65^{\circ} \mathrm{C}$. Isocratic separations used $4 \mathrm{mM}$ sulfuric acid at a rate of $0.4 \mathrm{~mL}$ per minute. Aqueous metabolite concentrations were calculated by regression analysis relative to standards. Cell dry weights (cdw) were determined using cell samples from midexponential phase cultures.

\section{Kinetic modeling}

Mathematica 10.0 package (Wolfram Research Inc., Champaign, IL, USA) was used to solve all ordinary differential equations, data fitting, calculating parameters with standard errors, and performing ANOVA sensitivity analysis. In Mathematica, the Fitmodel equation was used to perform 1000 iterations. The entire data were statistically analyzed by ANOVA to estimate standard error, t-statistic, and $P$-values. The $P$-value is the most critical parameter necessary to assess the quality of data fitting and must be below 0.05 to be statistically significant.

\section{T. maritima growth}

The growth of T. maritima was modeled assuming cell growth was dependent on first order kinetics:

$$
d X / d t=\mu X
$$

where $X$ was cellular biomass $\left(\mathrm{g} \mathrm{L}^{-1}\right), t$ was time $(\mathrm{h})$, and $\mu\left(\mathrm{h}^{-1}\right)$ was the proportionality constant generally known as the specific growth rate.

The doubling time of the individual cell lines was estimated using the condition: $X=2 X$ at $t=t_{d^{\prime}}$ where $t_{d}$ is the doubling time ( $\mathrm{h}$ in Eq (1):

$$
t_{d}=0.695 / \mu
$$


Monod's equation or the logistic approach [30] has been widely used for modeling growth. Here the logistic approach was used for modeling the growth of T. maritima due to its simplicity for calculation of batch fermentation data and the utilization of significant biological and bioreactor geometric parameters.

The logistic model can be presented as:

$$
d X / d t=\mu_{\max }\left(1-X / X_{\max }\right) X
$$

where $\mu_{\max }$ is the maximum specific growth rate $\left(\mathrm{h}^{-1}\right)$ and $X_{\max }$ is the maximum attainable biomass $\left(\mathrm{g} \mathrm{L}^{-1}\right)$. Applying initial condition: $X=X_{0}$ at $t=t_{0^{\prime}}$ Eq (3) can be simplified to the biomass equation:

$$
X=\frac{X_{0} X_{\max } e^{\mu_{\max } t^{t}}}{X_{\max }-X_{0}+X_{0} e^{\mu_{\max } t}}
$$

Product formation

The Leudking-Piret equation [30] was used to model the productions of $\mathrm{H}_{2}$ and acetate, where the rate of product formation was dependent on both growth and non-growth associated production, as shown in the following equation:

$$
d P / d t=\alpha d X / d t+\beta X
$$

where $P$ is the concentration of product i.e. $\mathrm{H}_{2}$ or acetate $\left(\mathrm{mmol} \mathrm{L}^{-1}\right)$, $\alpha$ is the growth associated coefficient $\left(\mathrm{mmol} \mathrm{g}^{-1}\right)$, and $\beta$ is the nongrowth associated coefficient $\left(\mathrm{mmol} \mathrm{g}^{-1} \mathrm{~h}^{-1}\right)$.

The formation of products can be divided into three different classes [31]: (i) Class I that represents products connected to biomass formation exclusively $(\alpha \neq 0 ; \beta=0)$, (ii) Class II that concerns products moderately connected with biomass formation $(\alpha \neq 0 ; \beta \neq 0)$, and (iii) Class III represents products that are unrelated to biomass formation $(\alpha=0 ; \beta \neq 0)$. The experimental data and modeling show that $\mathrm{H}_{2}$ and acetate formation by T. maritima fall into the Class II category.

\section{Maltose consumption}

An equation that describes maltose consumption can be represented by the utilization of the sugar in biomass formation, maintenance, and metabolite (product) formation: 


$$
-\frac{d S}{d t}=\frac{1}{Y_{X / S}} \frac{d X}{d t}+m X+\frac{1}{Y_{P / S}} \frac{d P}{d t}
$$

where $S$ is the substrate concentration $\left(\mathrm{mmol} \mathrm{L}^{-1}\right), Y_{X / S}$ is the biomass yield coefficient ( $\mathrm{g}$-biomass mmol-maltose $\left.{ }^{-1}\right), m$ is the maintenance coefficient (mmol g-1 $\mathrm{h}^{-1}$ ), and $Y_{P / S}$ is the product yield coefficient ( $\mathrm{g}$ biomass mmol-maltose ${ }^{-1}$ ). $\mathrm{H}_{2}$ and acetate productions in T. maritima can be related to biomass using the expression: $Y_{P / X}=-d P(t) / d X(t)$, where $Y_{P / X}$ is the yield of biomass-based product.

Sensitivity analysis

The parameters obtained from the modeling of biomass $\left(t_{d^{\prime}} \mu_{\text {max }} X_{\text {max }}\right)$, $\mathrm{H}_{2}$ production $\left(\alpha_{\mathrm{H} 2^{\prime}} Y_{\mathrm{H} 2 / \mathrm{S}}\right)$, acetate production $\left(\alpha_{A^{\prime}} \beta_{A^{\prime}} Y_{A / S}\right)$, and substrate (maltose) consumption $\left(m, Y_{X / S}\right)$ were calibrated and analyzed using ANOVA sensitivity analysis. Apart from the values of t-statistic, $P$-value, and $R^{2}$, the data were subjected to analysis with fitted residuals and estimated variance.

\section{Simulation of continuous $\mathrm{H}_{2}$ production}

Continuous $\mathrm{H}_{2}$ production was simulated with a continuous stirred tank reactor (CSTR) consistent with the experimental conditions. The assumptions for the continuous culture simulation were (i) the inflow stream to CSTR had a maltose concentration of $15 \mathrm{mM}$ with no biomass, (ii) the inflow and outflow were set to the same flow rate, and (iii) the respective calculated batch parameters for the three cell lines were assumed to be the same in the experimental conditions. The following equations were used to represent the growth, maltose consumption, and product formation ( $\mathrm{H}_{2}$ and acetate):

$$
\begin{gathered}
d X / d t=-D X+\mu X \\
\frac{d S}{d t}=D\left(S_{0}-S\right)-\left(\frac{1}{Y_{X / S}} \frac{d X}{d t}+m_{S} X+\frac{1}{Y_{P / S}} \frac{d P}{d t}\right) \\
P=Y_{P / X} X
\end{gathered}
$$

where $D$ is the dilution rate $\left(\mathrm{h}^{-1}\right)$, and $S_{0}$ is the initial substrate amount $\left(\mathrm{g} \mathrm{L}^{-1}\right)$. 


\section{Results and discussion}

\section{Kinetic modeling}

The kinetic modeling of growth (Equation (4)), $\mathrm{H}_{2}$ production (Equation (5)), acetate production (Equation (5)), and maltose utilization (Equation (6)) resulted in best-fit plots as shown in Fig. 2. The related kinetic parameters are listed in Table 1.

\section{Growth kinetics}

To maintain anaerobic conditions and to avoid $\mathrm{H}_{2}$ associated growth inhibition of the cell lines, the headspace of the bioreactor was continuously replaced by nitrogen $\left(\mathrm{N}_{2}\right)$ sparging at a constant rate of 15 $\mathrm{mL} \mathrm{min}{ }^{-1}$ throughout the duration of the fermentation. Fig. 2a shows

a)

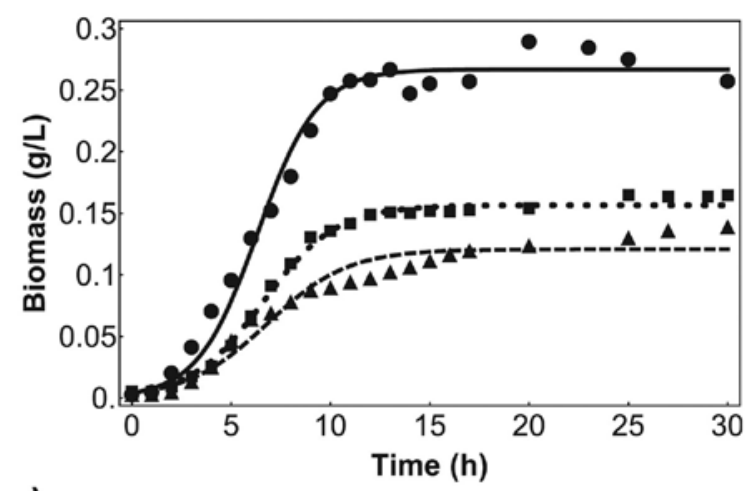

c)

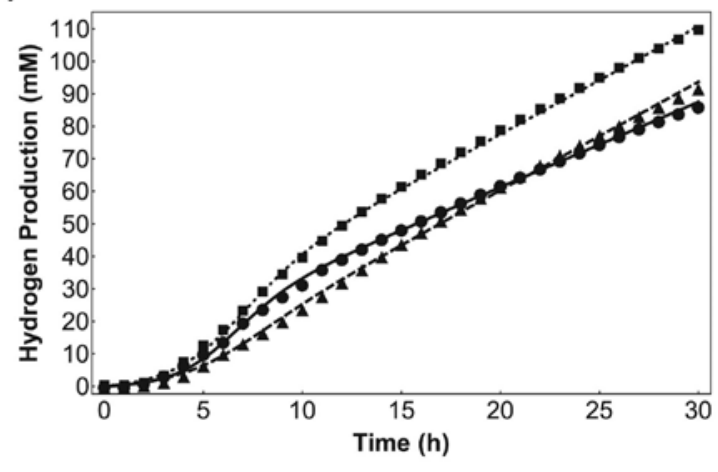

b)

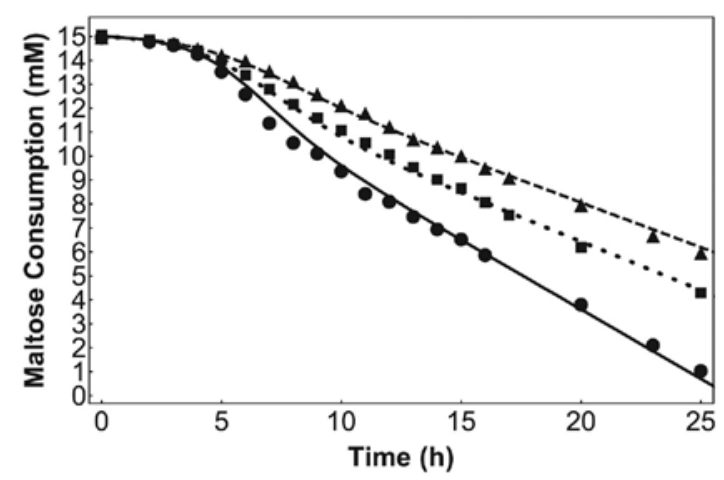

d)

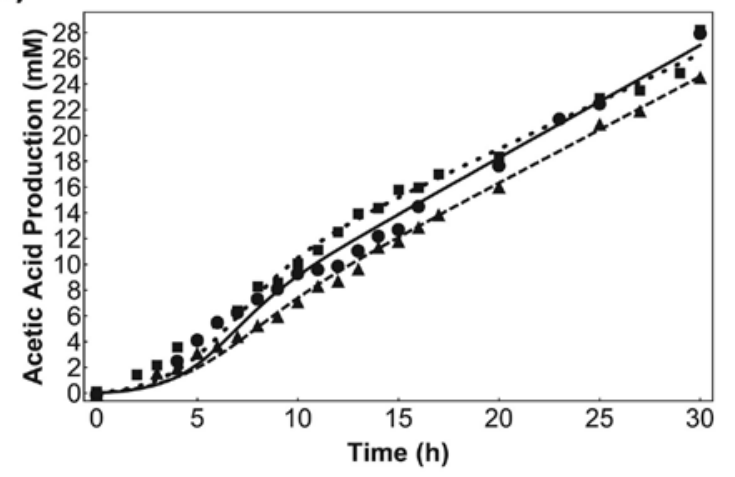

Fig. 2. Fitting of experimental data of growth, maltose consumption, $\mathrm{H}_{2}$ production and acetate production in wild type, Tma100 and Tma200 to the kinetic models. Experimental: wild type $(\bullet), \operatorname{Tma} 100(\boldsymbol{\Delta})$ and Tma200 (ם). Kinetic model fitted curves for wild type (-), Tma100 (- -) and Tma200 (...). 
Table 1. Fitted values of estimated parameters.

\begin{tabular}{|c|c|c|c|}
\hline \multirow[b]{2}{*}{ Parameters } & \multicolumn{3}{|c|}{ Thermotoga maritima strains } \\
\hline & Wild type & $\operatorname{Tma} 100$ & Tma200 \\
\hline \multicolumn{4}{|l|}{ (i) Biomass } \\
\hline Doubling time, $t_{d}(h)$ & 1.05 & 1.40 & 1.26 \\
\hline Maximum specific growth, $\mu_{\max }(1 / \mathrm{h})$ & $0.663 \pm 0.017$ & $0.495 \pm 0.022$ & $0.550 \pm 0.008$ \\
\hline Maximum biomass, $\mathrm{X}_{\max }(\mathrm{g} / \mathrm{L})$ & $0.267 \pm 0.004$ & $0.121 \pm 0.003$ & $0.157 \pm 0.001$ \\
\hline$R^{2}$ & 0.9961 & 0.9893 & 0.9988 \\
\hline \multicolumn{4}{|l|}{ (ii) $\mathrm{H}_{2}$ Production } \\
\hline $\mathrm{H}_{2}$ formation coefficient, $\alpha$ (mol- $\mathrm{H}_{2} / \mathrm{g}$-biomass) & $0.096 \pm 0.001$ & $0.142 \pm 0.004$ & $0.218 \pm 0.002$ \\
\hline $\mathrm{H}_{2}$ non- growth associated coefficient, $\alpha$ (mol- $\mathrm{H}_{2} / \mathrm{g}$-biomass) & $0.009 \pm 0.001$ & $0.028 \pm 0.001$ & $0.021 \pm 0.002$ \\
\hline Maximum $\mathrm{H}_{2}$ production (\% $\mathrm{cdw}$ ) & 4.30 & 7.96 & 10.20 \\
\hline Biomass based hydrogen yield, $\mathrm{Y}_{\mathrm{H} / \mathrm{X}}\left(\mathrm{mol}-\mathrm{H}_{2} / \mathrm{g}\right.$-biomass $)$ & $0.204 \pm 0.012$ & $0.435 \pm 0.023$ & $0.471 \pm 0.024$ \\
\hline$R^{2}$ & 0.9998 & 0.9997 & 0.9999 \\
\hline \multicolumn{4}{|l|}{ (iii) Acetate (AA) Production } \\
\hline AA formation coefficient, $\alpha$ (mol-AA/g- biomass) & $0.024 \pm 0.021$ & $0.047 \pm 0.025$ & $0.060 \pm 0.02$ \\
\hline AA non- growth associated coefficient, $\beta$ (mol-AA/(g-biomass * $h))$ & $0.0033 \pm 0.0002$ & $0.0068 \pm 0.0002$ & $0.0047 \pm 0.0002$ \\
\hline Biomass based AA yield, $\mathrm{Y}_{\mathrm{AAX} X}(\mathrm{~mol}-\mathrm{AA} / \mathrm{g}$-biomass) & $0.059 \pm 0.015$ & $0.112 \pm 0.026$ & $0.117 \pm 0.031$ \\
\hline$R^{2}$ & 0.9944 & 0.9981 & 0.9971 \\
\hline \multicolumn{4}{|l|}{ (iv) Maltose Consumption } \\
\hline Maximum biomass yield, $\mathrm{Y}_{\mathrm{x} / \mathrm{s}}(\mathrm{g}$-biomass/mol-maltose) & $30.4 \pm 1.05$ & $22.3 \pm 0.87$ & $24.5 \pm 0.93$ \\
\hline Maintenance coefficient, $m$ (g-biomass/(mol-maltose * $\mathrm{h}))$ & $0.370 \pm 0.063$ & $0.509 \pm 0.084$ & $0.940 \pm 0.071$ \\
\hline Substrate based $\mathrm{H}_{2}$ yield, $\mathrm{Y}_{\mathrm{H} 2 / 5}\left(\mathrm{~mol}-\mathrm{H}_{2} / \mathrm{mol}\right.$-maltose $)$ & $6.22 \pm 0.13$ & $9.69 \pm 0.20$ & $11.54 \pm 0.22$ \\
\hline Substrate based AA yield, $Y_{A A / S}(\mathrm{~mol}-\mathrm{A} / \mathrm{mol}$-maltose $)$ & $1.82 \pm 0.02$ & $2.66 \pm 0.02$ & $2.87 \pm 0.02$ \\
\hline$R^{2}$ & 0.9998 & 0.9999 & 0.9999 \\
\hline Ratio $\left(\mathrm{H}_{2} / \mathrm{AA}\right)$ & 3.41 & 3.64 & 4.02 \\
\hline
\end{tabular}

AA - Acetic Acid; $\mathrm{H}_{2-}$ Hydrogen gas.

the fitting of the experimental growth data using Equation (4). The ANOVA analysis ( $p$-values $<0.05)$ and optimal fitting $\left(R^{2}\right.$ value of 0.99$)$ of the data confirm the reliability of the model. As evident by the initial slopes of growth curves shown in Fig. 2a, the model fitting demonstrated higher parametric determination of specific growth rates in the wild type followed by Tma200 (approximately 75\% lower than wild type) and finally by Tma100 (approximately $83 \%$ lower than wild type). These variable growth rates resulted in approximately $45 \%$ and 59\% lower overall biomass for Tma100 and Tma200 than that of the wild type, respectively. The differences in values of the biomass production rates observed between the cell lines were due to different doubling times and specific growth rates as listed in Table $\mathbf{1}$ and were independent of $\mathrm{H}_{2}$-associated growth inhibition [20] since a continuous flow of $\mathrm{N}_{2}$ avoided $\mathrm{H}_{2}$ accumulation [16]. Biomass based productivity of $\mathrm{H}_{2}\left(96 \mathrm{mmol} \mathrm{H}_{2} \mathrm{~g}^{-1} \mathrm{cdw}\right.$ ) in the wild type was comparable with prior fermentation studies (94 $\mathrm{mmol} \mathrm{g}^{-1} \mathrm{cdw}$ ) carried out with $T$. maritima [32]. 
Relationships between maltose consumption, growth and product formation

The maltose consumption rates, growth and product yields were estimated on the basis of limiting substrate (maltose) utilization during fermentation. The experimental values of maltose consumption in the cell lines were fitted $\left(p<0.05\right.$ and $\left.R^{2}=0.99\right)$ for their respective experimental data points using Equation (6) (Fig. 2b). The wild type grew faster (specific growth rate $=0.663 \mathrm{~h}^{-1}$ ) and therefore utilized more than $95 \%$ of the available maltose in $30 \mathrm{~h}$ of fermentation. The reduction in the growth rates of Tma100 $\left(0.495 \mathrm{~h}^{-1}\right)$ and Tma200 $\left(0.550 \mathrm{~h}^{-1}\right)$ was consistent with a slower rate of maltose uptake and consumption. The poor growth of Tma100 resulted in a residual amount of unutilized maltose $(6.75 \mathrm{mM})$ in the bioreactor after $30 \mathrm{~h}$ of fermentation. Tma200 showed an intermediate growth pattern again resulting in a residual amount of unutilized maltose $(4.70 \mathrm{mM})$. The reason for the residual maltose was due to a slower maltose uptake by the mutated maltose transporter of Tma100 and Tma200 [25].

It has been reported that non-growing or slowly growing microbial cultures can recycle much of the metabolic energy derived from the initial fermentation of sugar into driving additional $\mathrm{H}_{2}$ production [33]. To determine if this might be occurring in this study, we determined the amount of substrate utilized for non-growing biomass and the maintenance coefficient for all three strains (Table 1). The estimated values of the maintenance coefficients showed that Tma100 and Tma200 strains utilized $\sim 1.37$ and $\sim 2.54$-fold more maltose respectively than the wild type for their non-growing components that contributed towards the formation of comparatively higher fermentation products than that of wild type. Importantly, fermentations in fermentative organisms have been optimized by evolution to produce cell biomass and not $\mathrm{H}_{2}$ [34]. This has been a major obstacle for the production of biological $\mathrm{H}_{2}$ in an economically viable manner but could be overcome if $\mathrm{H}_{2}$ formation could be uncoupled from biomass formation and cell growth. From the data presented here it was evident that a greater proportion of maltose contributed to formation of fermentative products $\left(\mathrm{H}_{2}\right.$ and acetate) rather than biomass in strains Tma100 and Tma200 and was accompanied by slower growth (Table 1). The higher $\mathrm{g} \mathrm{cdw} \mathrm{mol}^{-1}$ maltose ratio in the wild type indicated that the maltose consumed by the wild type strain resulted in 
an excess of biomass formation in deference to formation of fermentative products including $\mathrm{H}_{2}$ (Fig. 5).

To observe the amount of fermentative products $\left(\mathrm{H}_{2}, \mathrm{CO}_{2}\right.$ and acetate) synthesized by the strains (Tma100 and Tma200) [25], the substrate-based product yields were calculated. Tma100 and Tma200 were found to be superior in $\mathrm{H}_{2}$ and acetate yields as compared to the wild type; the yields of $\mathrm{H}_{2}$ production were $\sim 1.56$ and $\sim 1.86$-fold higher, respectively, whereas acetate yields were $\sim 1.46$ and $\sim 1.58$-fold higher, respectively compared with the wild type. Tma100 and Tma200 were also found to produce 1.40 -fold and 1.65 fold higher molar yield of $\mathrm{CO}_{2}$ than the wild type suggesting increased oxidation of the sugar.

Relationship of $\mathrm{H}_{2}$ production to kinetic parameters determined from biomass formation and maltose consumption

To obtain $\mathrm{H}_{2}$-related kinetic parameters such as the $\mathrm{H}_{2}$ formation coefficient, maximum production, and maximum yield, the experimental data for $\mathrm{H}_{2}$ production for each cell line were fitted using the Leudking-Piret Equation (5) as shown (Fig. 2c). The fitted values for these parameters are listed in Table 1. The statistical analysis $(p<0.05)$ and model fitting $\left(R^{2}=0.99\right)$ verified a higher confidence in the predictions. It was observed that the $\mathrm{H}_{2}$ formation coefficient (a), that represented growth-associated $\mathrm{H}_{2}$ production, remained $\sim 1.53$ and 2.26-fold higher for Tma100 and Tma200 relative to the wild type, respectively. This highlighted that $\mathrm{H}_{2}$ formation was growth dependent, which was greater for Tma100 and Tma200 even though their growth rates were lower than that of the wild type. This could mean that production of $\mathrm{H}_{2}$ in Tma100 and Tma200 was higher on a per cell basis. The production of $\mathrm{H}_{2}$ in the stationary phase is represented by $b$, which is the non-growth $\mathrm{H}_{2}$ coefficient. A comparatively low value of $b$ for the wild type than that of Tma100 and Tma200 suggested that $\mathrm{H}_{2}$ production remained lower in the wild type under non-growth conditions, while Tma100 and Tma200 produced $\mathrm{H}_{2}$ constantly even under non-growth conditions. This underscores a unique capacity of Tma100 and Tma200 to produce $\mathrm{H}_{2}$ continuously and concomitantly with slow biomass production. To determine the value for $\mathrm{H}_{2}$ production per unit biomass, the respective exponential growth phase values of $\mathrm{H}_{2}$ were linearly regressed (Fig. 3). The slopes represented the 


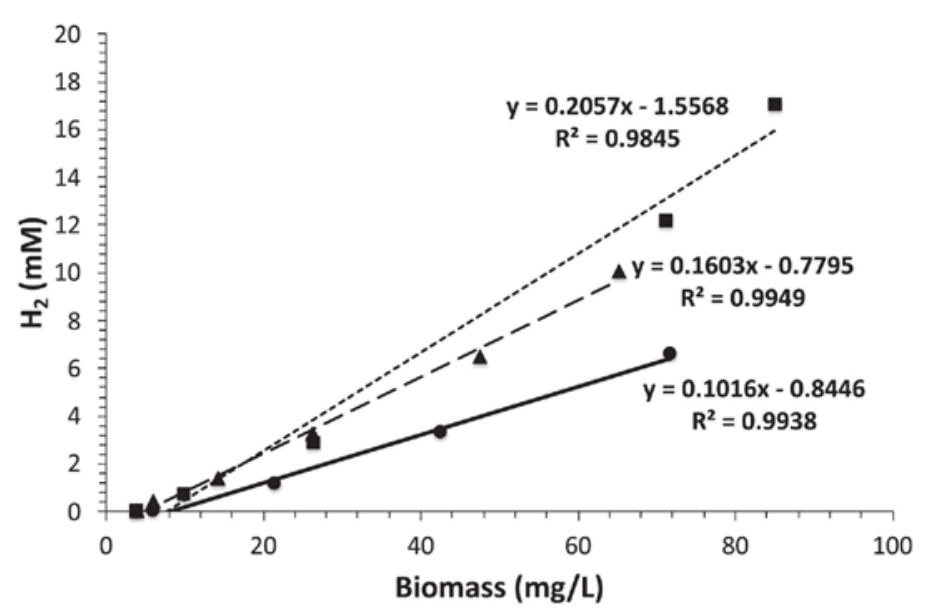

Fig. 3. Relationship between biomass and $\mathrm{H}_{2}$ production for wild type, Tma100 and Tma200. The slope represents the $\mathrm{H}_{2}$ production rate per $\mathrm{mg} \mathrm{cdw} \mathrm{L-1}$ biomass.

$\mathrm{H}_{2}$ production per mg-cdw. The higher slopes of $\mathrm{H}_{2}$ production for Tma200 (2 fold) and Tma100 (1.6 fold) relative to the wild type were also consistent with higher $\mathrm{H}_{2}$ productivity per unit biomass. The intercept, representing the minimum concentration of biomass (on a cdw basis) that evolved $\mathrm{H}_{2}$ and was found to be twice as high for Tma200 (1.56 $\left.\mathrm{mg} \mathrm{L}^{-1}\right)$ relative to those of both the wild type $\left(0.84 \mathrm{mg} \mathrm{L}^{-1}\right)$ and Tma100 $\left(0.78 \mathrm{mg} \mathrm{L}^{-1}\right)$. Therefore, the results indicated that a lower quantity of biomass and corresponding growth resulted in $\mathrm{H}_{2}$ overproduction by Tma100 and Tma200 (Fig. 5). This is consistent with prior studies in other organisms where reducing the substrate feeding to decrease biomass resulted in higher $\mathrm{H}_{2}$ production [35]. As reported previously, the differential growth patterns observed for wild type, Tma100 and Tma200 were a result of their respective ability to transport and ferment maltose [25]. Based on the modeling reported here, $\mathrm{H}_{2}$ production was a function of both growth and maltose utilization, and a reduction in both yielded more fermentative products.

A kinetic and redirected metabolism pathway-based explanation for the higher molar yield of $\mathrm{H}_{2}$

The most interesting outcome from studies using Tma100 and Tma200 was that $\mathrm{H}_{2}$ production per $\mathrm{g} \mathrm{cdw}$ increased relative to the wild type and the molar yield of $\mathrm{H}_{2}$ surpassed the previously 
proposed limit of $4 \mathrm{~mol}$ of $\mathrm{H}_{2}$ per hexose [19]. For Tma100, the ratio of moles of $\mathrm{H}_{2}$ per mole of maltose was $9.69 \pm 0.20$ and for Tma200 the ratio was $11.54 \pm 0.22$. This confirms the hydrogen yield to go beyond the predicted Thauer limit. (Table 2). It also emphasizes the unique nature of these strains.

Higher values of $\mathrm{H}_{2}$ formation coefficient in combination with higher non-growth $\mathrm{H}_{2}$ coefficients for Tma100 and Tma200 suggested that $\mathrm{H}_{2}$ production in these strains was a continuous process. This could be one of the kinetic modeling-based explanations of the higher molar yield of $\mathrm{H}_{2}$. Furthermore, the maintenance energy coefficient, (a physiological parameter) that specifies the amount of energy cells require for maintaining homeostasis in the absence of growth [36], was found to be twice as high for Tma100 and three times higher for Tma200 relative to that of the wild type. This suggests that energy from maltose catabolism is used to maintain the cellular integrity of Tma100 and Tma200 instead of being used for cellular multiplication. A relationship of higher maintenance coefficients to the highest yields of $\mathrm{H}_{2}$ is consistent with prior studies in other hyperthermophiles [37].

The direction of the carbon flux through the Entner-Doudoroff (ED) or Embden-Meyerhof-Parnas (EMP) or the Pentose Phosphate Pathway (PPP) can determine the amount of $\mathrm{H}_{2}$ and other metabolites. Normally, T. maritima utilizes the EMP (85\%) and the ED (15\%) pathways without using the PPP ultimately leading to a maximum production of $4 \mathrm{~mol}$ of $\mathrm{H}_{2}$ and $2 \mathrm{~mol}$ of acetate per mol of glucose consumed [14]. If the carbon flux is rerouted through the PPP, the additional reductants can be produced leading to either $8 \mathrm{~mol} \mathrm{H}_{2}$ per mole of glucose (maximum) along with 1 mol acetate per mole of glucose ${ }^{-1}$ or $5.33 \mathrm{~mol} \mathrm{H}_{2}$ mol-1 $^{-1}$ glucose (minimum) along with 1.67 mol acetate per mole of glucose depending on reutilization of intermediates (Fig. S1). The carbon flux is rerouted through the PPP in the engineered strains and the glycolytic pattern resembles the letter " $p$ ". This can be defined as the p-type metabolism that results in maximum hydrogen productivity. In contrast, carbon flows through the EMP and ED pathway in the wild type and the overall carbon flow pattern resembles the letter "q". This can be defined as the q-type metabolism that is less productive (Fig. 5). The production of ATP is an important consideration because it is required to sustain bacterial growth. Generation of $8 \mathrm{~mol} \mathrm{H}_{2} \mathrm{~mol}^{-1}$ glucose leads to $1 \mathrm{~mol}$ ATP formation whereas $5.33 \mathrm{~mol} \mathrm{H}_{2} \mathrm{~mol}^{-1}$ glucose leads to $1.63 \mathrm{~mol}$ ATP (Fig. S1). The lower 


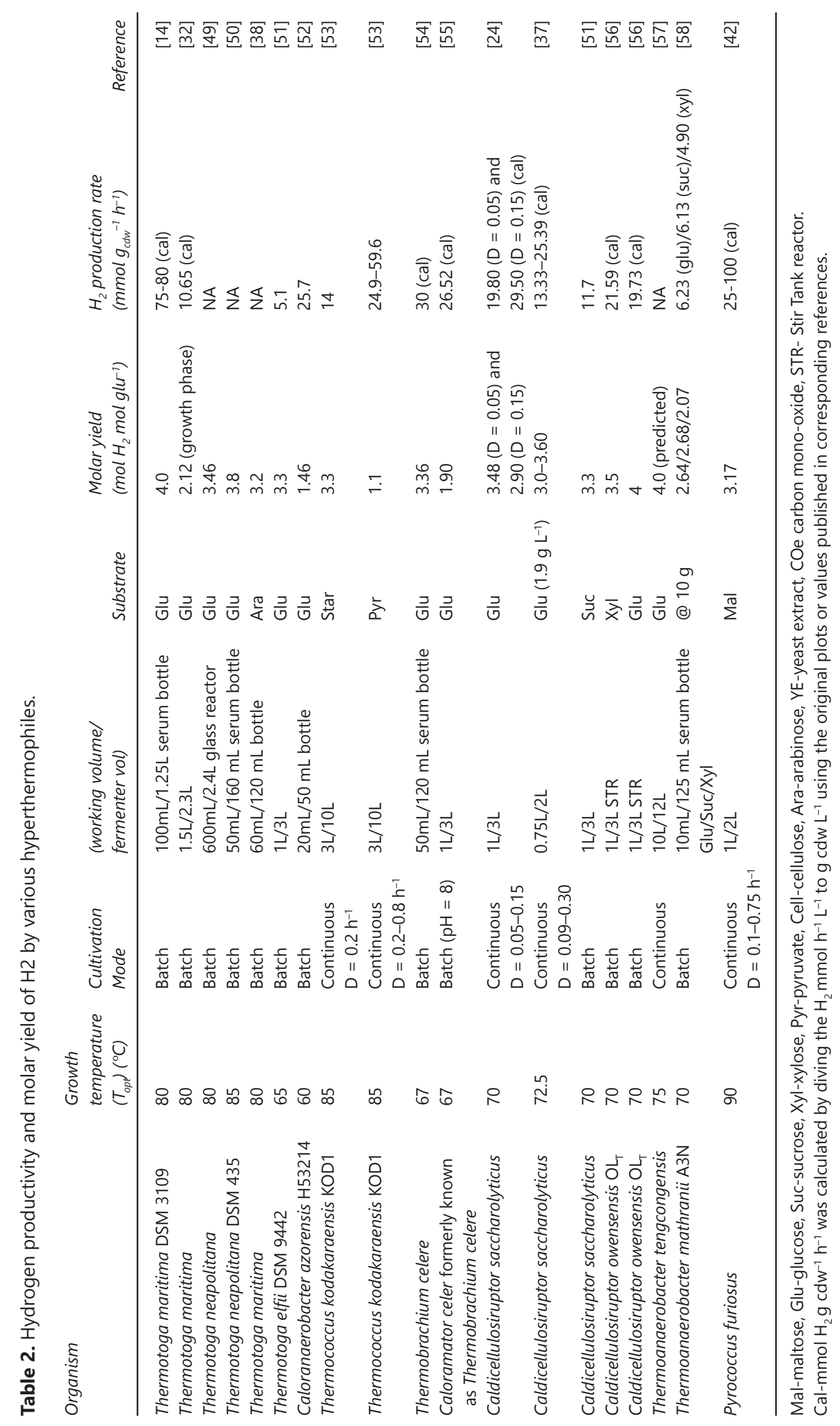




\section{Dilution Rate}
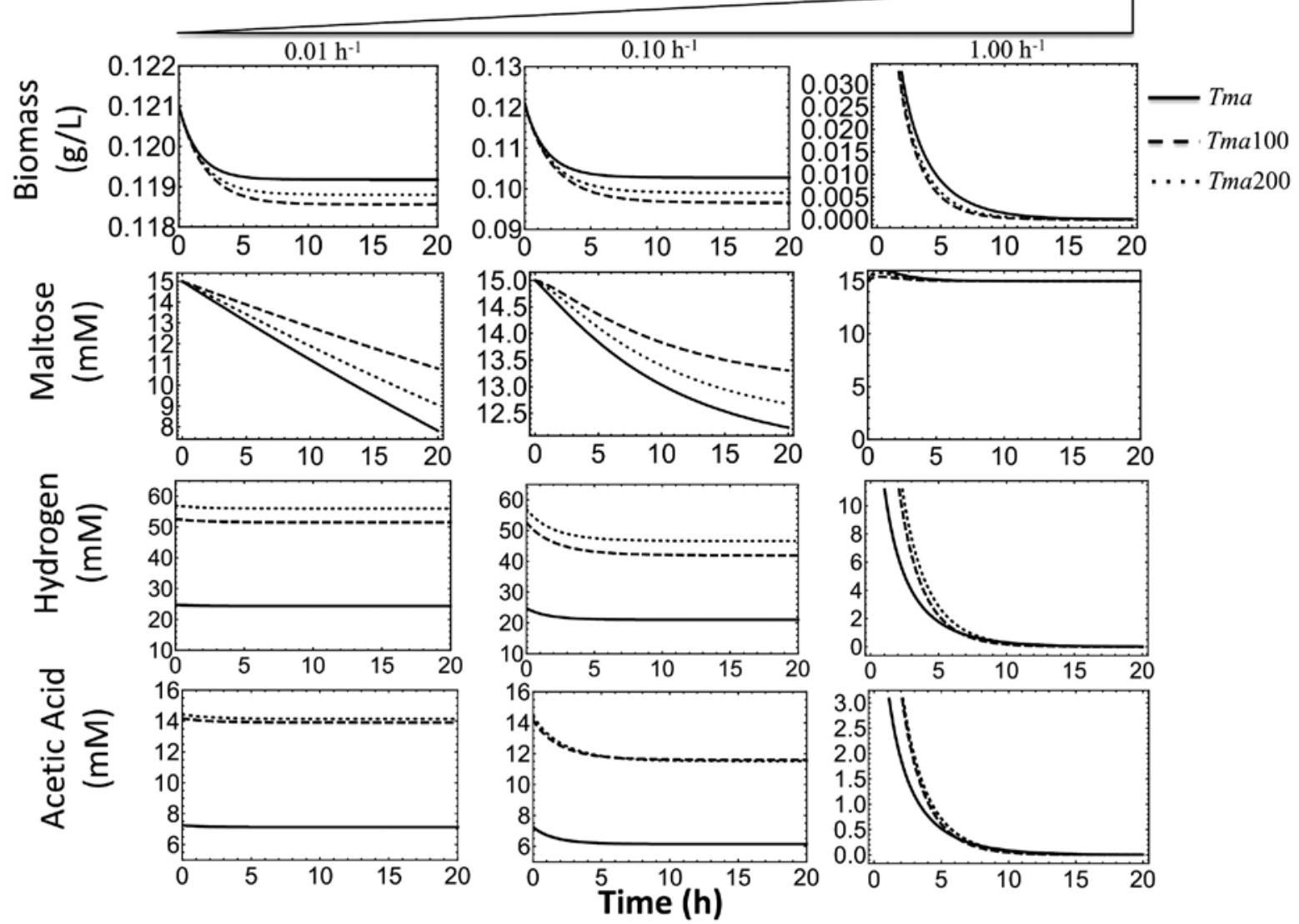

Fig. 4. Continuous flow simulation for biomass, maltose utilization, $\mathrm{H}_{2}$ production

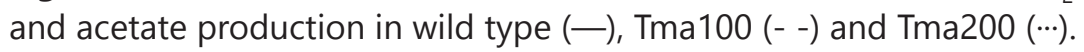

amount of ATP production does not offer any benefit to a fermentative bacterium instead it is likely to affect growth negatively. The organism would prefer to extract the maximum amount of ATP when carbon is redirected through the PPP. This was the case for Tma200 that generated $5.77 \mathrm{~mol} \mathrm{H}_{2}$ mol-1 $^{-1}$ glucose and $1.87 \mathrm{~mol}$ acetate mol-1 glucose representing the attainment of a stable metabolic condition that could generate enough ATP to sustain growth while synthesizing $\mathrm{H}_{2}$ above the previously proposed hypothetical limit. In addition to the involvement of the PPP, the overall Gibbs free energy change for the metabolic reactions for Tma100 and Tma200 remained supportive of enough ATP formation and excess $\mathrm{H}_{2}$ production [25].

Physiologically, a metabolic shift towards acetate offers another plausible reason of the increased $\mathrm{H}_{2}$ molar yield by Tma100 and 


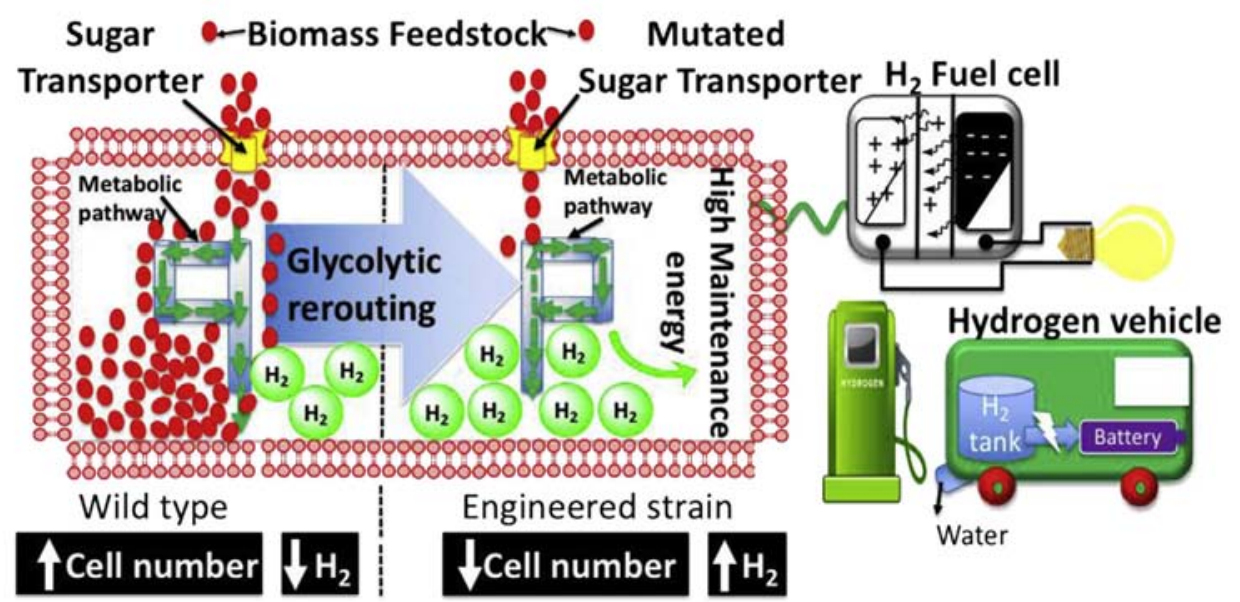

Fig. 5. A proposed model explaining feedstock uptake and the resultant metabolic transition from the letter " $q$ " shaped ( $q$-type metabolism) to " $p$ " shaped ( $p$-type metabolism). The wild type accumulates excessive carbon that forces q-type metabolism which is created by the use of the EMP pathway. In the engineered strain uptake of carbon is slow which activates $p$-type metabolism formed by the use of the PPP. Redirection of energy consumption from cell reproduction to maintenance energy enables more $\mathrm{H}_{2}$ formation than the cell mass and the opposite is true in the wild type. Hydrogen can be used either to generate energy via a fuel cell or as a fuel for the hydrogen vehicles.

Tma200. In the absence of any detectable ethanol production [38] and a reduced quantity of lactate formation (none for Tma100 and a 75\% reduction for Tma200 relative to the wild type) it appears that metabolism has been redirected in Tma100 and Tma200. A metabolic shift has been observed in different knockout mutants of another organism [39], however, in the present study this metabolic shift seems to occur as a result of variable maltose uptake and growth in Tma100 and Tma200. Prediction of the molar yield of acetate and a non-growth associated coefficient by Leudking-Piret equation verified the metabolic shift in Tma100 and Tma200 (Table 1).

\section{Acetic acid production and kinetic parameters}

In a fermentative $\mathrm{H}_{2}$ producing organism, organic acid excretion can determine the effectiveness of $\mathrm{H}_{2}$ production. A metabolic shift towards lactate production decreased the $\mathrm{H}_{2}$ production rate [40] whereas an increase in acetate improved the $\mathrm{H}_{2}$ production rate $[12,41]$. As no lactate was produced by Tma100 whereas a reduction 
of $75 \%$ of lactate was observed in Tma200, only the experimental data for acetate formation was modeled. Previously, in small batch culture studies, the molar yield of acetate has been reported to be 2 mol mol-1 glucose in T. maritima [14]. However using a larger scale

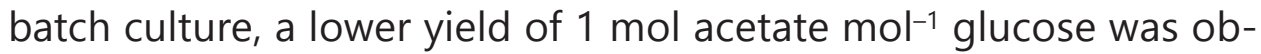
served [32]. Furthermore, in a chemostat study of Pyrococcus furiosus, a yield of $1.27 \mathrm{~mol}$ of acetate per mole of glucose was reported [42]. This suggested that the theoretical value of $2 \mathrm{~mol}$ of acetate mol${ }^{-1}$ of glucose may not be achieved using a larger scale of batch cultivation. In this study, however, the molar yield of acetate for wild type was estimated to be $0.90 \mathrm{~mol} \mathrm{~mol}^{-1}$ of glucose $\left(1.82 \pm 0.02 \mathrm{~mol} \mathrm{~mol}^{-1}\right.$

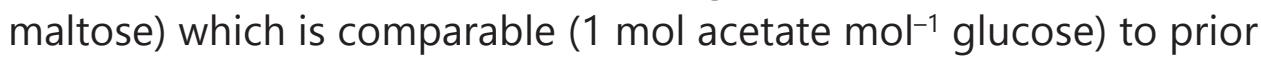
larger scale batch culture studies [32]. Additionally, a lower theoretical molar yield of acetate could result from a loss of carbon as L-alanine excretion as has been reported previously in T. maritima [32,43]. Since $\mathrm{H}_{2}$ production was tightly linked to acetate production, a proportional increase in the acetate molar yield was achieved by Tma100 and Tma200. The overall yields of acetate in both engineered strains were very close to as predicted by the involvement of the PPP (Fig. S1). The model fitting of the acetate produced by the strains (Fig. 2d) showed that acetate was both a growth and non-growth associated product. The growth associated coefficient $(\alpha)$ increased 1.96 and 2.50-times for Tma100 and Tma200, respectively relative to the wild type (Table 1). The values of non-growth associated growth $(\beta)$ increased by 2.06 and 1.42 -fold for Tma100 and Tma200, respectively relative to the wild type (Table 1). Biomass-based acetate yield by Tma100 and Tma200 was 1.98-fold higher than that of the wild type (Table 1). Carbon recovery was over $90 \%$ indicating a balanced stoichiometry and indicated that the major carbon source was maltose while other carbon present in yeast extract added to the growth medium did not contribute significantly to fermentation product formation [25]. A separate validation of the fermentation was pursued by calculating the oxidation-reduction balance of the overall fermentation reaction for all strains. The oxidation-reduction balance of oxidized and reduced products was close to the theoretical value of 1.0. This showed that the products were in balance and were accurately determined without any indication of new products present in significant quantities [25]. 


\section{Simulation of a continuous biohydrogen production system}

Growth simulation in a bioreactor

Kinetic modeling can provide a comprehensive analysis of experimental data to predict operating conditions [44] that are required for continuous fermentation. Continuous culture studies are crucial to achieve a more stable and higher yield of productivity $([45,46]$. Since, $\mathrm{H}_{2}$ is mostly a growth dependent product, a continuous stirred tank reactor (CSTR) may be the best choice for continuous $\mathrm{H}_{2}$ production. Here, kinetic modeling of the bioreactor-based experimental data was used to estimate various kinetic parameters to define $\mathrm{H}_{2}$-specific attributes necessary for $\mathrm{H}_{2}$ over-producing strains. These became the basis for simulating a continuous $\mathrm{H}_{2}$ production system.

The dilution rate $(D)$ is an important factor that maintains cultivated organisms in their most productive phase leading to stabilization of the continuous culture-based system [47]. To predict a stable system for $\mathrm{H}_{2}$ production, the determined kinetic parameters were employed to simulate a continuous stirred tank reactor. For the simulation of continuous $\mathrm{H}_{2}$ production, Equations (7)-(9) were solved using the parameters for the respective strains as listed in Table 1. The comparative simulation results for all the cell lines at three different dilution rates are presented in Fig. 4. A lower dilution rate $\left(0.01 \mathrm{~h}^{-1}\right)$ maintained a majority of the biomass $(\sim 119.6,118.8$, and $118.6 \mathrm{mg}$ $\mathrm{L}^{-1}$ of wild type, Tma200 and Tma100, respectively) compared to the dilution rate of $0.1 \mathrm{~h}^{-1}\left(\sim 100.6,100.0\right.$, and $109.6 \mathrm{mg} \mathrm{L}^{-1}$ of wild type, Tma200 and Tma100, respectively). Both lower rates (0.01 and $0.1 \mathrm{~h}^{-1}$ ) were likely to maintain a steady state after $5 \mathrm{hr}$ until the end of the fermentation. A higher dilution rate $\left(1 \mathrm{~h}^{-1}\right)$ would result in a loss of significant biomass. The loss of biomass at a higher dilution rate can be attributed to the higher dilution rate (D) that approached the value of $\mu_{\max }$ (Table 1). Consequently, at a higher dilution rate, the continuous culture system is predicted to become unstable due to washout of the biomass.

\section{Simulation of maltose consumption during continuous cultivation}

The effect of dilution rate on maltose consumption was estimated at three dilution rates. At a lower dilution rate, due to the presence of a 
higher number of cells in the bioreactor, an excess of substrate utilization was likely. From a simulation plot of maltose consumption, it was evident that a lower dilution rate $\left(0.01 \mathrm{~h}^{-1}\right)$ would result in fast utilization of maltose in the wild type with a slower rate of consumption by Tma100 and Tma200. Therefore, the inherent ability of Tma100 and Tma200 to utilize less maltose makes them more economic in regard to substrate utilization. Since, bioreactor washout is predicted to occur at $1.0 \mathrm{~h}^{-1}$, no maltose utilization would take place even in the presence of $15 \mathrm{mM}$ maltose.

\section{$\mathrm{H}_{2}$ production simulation in a bioreactor}

At a lower dilution rate $\left(0.01 \mathrm{~h}^{-1}\right) \mathrm{H}_{2}$ production would remain constant without any fluctuation and the $\mathrm{H}_{2}$ production rate would be significantly higher in Tma100 and Tma200 relative to that of the wild type. At an intermediate flow rate $\left(0.1 \mathrm{~h}^{-1}\right) \mathrm{H}_{2}$ production would fluctuate and would collapse at $1 \mathrm{~h}^{-1}$ due to washout of cells as has been seen in CSTR simulation studies on $\mathrm{H}_{2}$ production [48]. This suggested that maintaining a flow rate of $0.01 \mathrm{~h}^{-1}$ would retain the optimum number of cells of Tma100 (118.6 $\mathrm{mg} \mathrm{L}^{-1}$ ) and Tma200 (118.8 $\left.\mathrm{mg} \mathrm{L}^{-1}\right)$ thereby, allowing them to produce more $\mathrm{H}_{2}$ than that of the wild type at a reduced rate of maltose utilization. From this observation, it was reasonable to conclude that maintaining a lower biomass for the wild type (equivalent to Tma100 and Tma200) could improve $\mathrm{H}_{2}$ production by the wild type organism. However, as the only way to maintain a lower biomass of the wild type would be to increase the flow rate, it is evident from the simulation that an increase in flow rate will decrease $\mathrm{H}_{2}$ production even though the biomass of the wild type will become equivalent to strains Tma100 or Tma200 at the steady state. This supports the notion that the productions of $\mathrm{H}_{2}$ from Tma100 and Tma200 are higher on a per cell basis and will remain higher than that of wild type under any kinetic condition.

\section{Acetic acid production simulation in a bioreactor}

Similar to $\mathrm{H}_{2}$ production, a proportional amount of acetate would be produced under continuous cultivation conditions and the overall concentration would be higher than that of the wild type. A higher dilution rate $\left(1 \mathrm{~h}^{-1}\right)$ would result in a decrease of acetate due to wash 
out of acetate producers. This simulation-based prediction considered results obtained from an experimental batch study [48]. From the overall simulation, a dilution rate of $\left(0.1 \mathrm{~h}^{-1}\right)$ would be suitable for a constant amount of $\mathrm{H}_{2}$ production in the continuous culture. As excess $\mathrm{H}_{2}$ production is an inherent property of Tma100 and Tma200, and the wild type cannot achieve this despite manipulation of cultivation conditions, the evolved T. maritima cell lines are ideal candidates for economic and large scale $\mathrm{H}_{2}$ production.

\section{Conclusions}

The kinetic modeling of product formation by Thermotoga maritima cell lines (wild type, Tma100, and Tma200) presents the relationship between maltose utilization, biomass production, and the syntheses of $\mathrm{H}_{2}$ and acetate. Fitting of the experimental data showed that the excess $\mathrm{H}_{2}$ production by Tma100 and Tma200 resulted from the contributions of growth and non-growth coefficients. The slow growth of Tma100 and Tma200 resulted from their reduced maltose uptake rates that shifted the $\mathrm{q}$-type metabolism to $\mathrm{p}$-type metabolism in these strains. The kinetic parameters were used to simulate a continuous and stable culture-based $\mathrm{H}_{2}$ production system. Besides, the study suggests an improved design for large-scale biological hydrogen system.

Acknowledgments - This research was supported by funds from the U.S. Department of Energy (DEPS02-08ER08-12) and the UNL Cell Development Facility to PB. We thank Robert M. Kelly and Christopher Straub, North Carolina University for providing us detailed information on the carbon flux redirected through the pentose phosphate pathway and resultant $\mathrm{H}_{2}$ yield.

Appendix A. Supplementary data - Supplementary Figures 1 and 2 follow the References.

\section{References}

[1] Das D. Advances in biohydrogen production processes: an approach towards commercialization. Int J Hydrogen Energy 2009; 34: 7349-57. 
[2] Gurz M, Baltacioglu E, Hames Y, Kaya K. The meeting of hydrogen and automotive: A review. Int J Hydrogen Energy 2017; 42: 23334-46.

[3] Dutta S. A review on production, storage of hydrogen and its utilization as an energy resource. J Ind Eng Chem 2014; 20: 1148-56.

[4] Hames Y, Kaya K, Baltacioglu E, Turksoy A. Analysis of the control strategies for fuel saving in the hydrogen fuel cell vehicles. Int J Hydrogen Energy 2018; 43: 10810-21.

[5] Sinha P, Pandey A. An evaluative report and challenges for fermentative biohydrogen production. Int J Hydrogen Energy 2011; 36: 7460-78.

[6] Ehret O, Bonhoff K. Hydrogen as a fuel and energy storage: Success factors for the German Energiewende. Int J Hydrogen Energy 2015; 40: 5526-33.

[7] Coren MJ. Nine countries say they'll ban internal combustion engines. So far, it's just words. Quartz, August 7, 2018. [ https://qz.com/1341155/ninecountries-say-they-will-ban-internal-combustion-engines-none-have-a-lawto-do-so/; Accessed 29 December 2018].

[8] Singh M, Moore J, Shadis W. Hydrogen demand, production, and cost by region to 2050. Argonne, IL USA: Argonne National Laboratory; 2005.

[9] Hallenbeck P. Bioenergy from microorganisms: an overview. In: Zannoni D, De Philippis R, editors. Microbial bioenergy: hydrogen production. Netherlands: Springer; 2014. p. 3-21.

[10] Hallenbeck PC, Ghosh D. Advances in fermentative biohydrogen production: the way forward? Trends Biotechnol 2009; 27: 287-97.

[11] Chou CJ, Jenney Jr FE, Adams MW, Kelly RM. Hydrogenesis in hyperthermophilic microorganisms: implications for biofuels. Metab Eng 2008; 10: 394-404.

[12] Nath K, Das D. Improvement of fermentative hydrogen production: various approaches. Appl Microbiol Biotechnol 2004; 65: 520-9.

[13] Selig M, Xavier KB, Santos H, Schonheit P. Comparative analysis of EmbdenMeyerhof and Entner-Doudoroff glycolytic pathways in hyperthermophilic archaea and the bacterium Thermotoga. Arch Microbiol 1997; 167: 217-32.

[14] Schröder C, Selig M, Schönheit P. Glucose fermentation to acetate, CO2 and $\mathrm{H} 2$ in the anaerobic hyperthermophilic eubacterium Thermotoga maritima: involvement of the Embden-Meyerhof pathway. Arch Microbiol 1994; 161: 460-70.

[15] van Niel EW, Claassen PA, Stams AJ. Substrate and product inhibition of hydrogen production by the extreme thermophile, Caldicellulosiruptor saccharolyticus. Biotechnol Bioeng 2003; 81: 255-62.

[16] Nguyen TA, Han SJ, Kim JP, Kim MS, Sim SJ. Hydrogen production of the hyperthermophilic eubacterium, Thermotoga neapolitana under N2 sparging condition. Bioresour Technol 2010; 101(Suppl 1): S38-41.

[17] Mizuno O, Dinsdale R, Hawkes FR, Hawkes DL, Noike T. Enhancement of hydrogen production from glucose by nitrogen gas sparging. Bioresour Technol 2000; 73: 59-65.

[18] Show K-Y, Lee D-J, Chang J-S. Bioreactor and process design for biohydrogen production. Bioresour Technol 2011; 102: 8524-33.

[19] Thauer RK, Jungermann K, Decker K. Energy conservation in chemotrophic anaerobic bacteria. Baceriol Rev 1977; 41: 100-80. 
[20] Huber R, Langworthy T, König $H$, Thomm M, Woese $C$, Sleytr U, et al. Thermotoga maritima sp. nov. represents a new genus of unique extremely thermophilic eubacteria growing up to $90^{\circ} \mathrm{C}$. Arch Microbiol 1986; 144 : 324-33.

[21] Chhabra SR, Shockley KR, Conners SB, Scott KL, Wolfinger RD, Kelly RM. Carbohydrate-induced differential gene expression patterns in the hyperthermophilic bacterium Thermotoga maritima. J Biol Chem 2003; 278 : 7540-52.

[22] Singh R, White D, Blum P. Identification of the ATPase subunit of the primary maltose transporter in the hyperthermophilic anaerobe Thermotoga maritima. Appl Environ Microbiol 2017; 83.

[23] Schut GJ, Adams MW. The iron-hydrogenase of Thermotoga maritima utilizes ferredoxin and NADH synergistically: a new perspective on anaerobic hydrogen production. J Bacteriol 2009; 191: 4451-7.

[24] Willquist K, Pawar SS, Van Niel EW. Reassessment of hydrogen tolerance in Caldicellulosiruptor saccharolyticus. Microb Cell Factories 2011; 10. 111-2859-10-111.

[25] Singh R, White D, Demirel Y, Kelly R, Noll K, Blum P. Uncoupling fermentative synthesis of molecular hydrogen from biomass formation in Thermotoga maritima. Appl Environ Microbiol 2018; 84.

[26] Nath K, Das D. Modeling and optimization of fermentative hydrogen production. Bioresour Technol 2011; 102: 8569-81.

[27] Ghimire A, Frunzo L, Pirozzi F, Trably E, Escudie R, Lens PNL, et al. A review on dark fermentative biohydrogen production from organic biomass: process parameters and use of byproducts. Appl Energy 2015; 144: 73-95.

[28] Singh R, Gradnigo J, White D, Lipzen A, Martin J, Schackwitz W, et al. Complete genome sequence of an evolved Thermotoga maritima isolate. Genome Announc 2015; 3.

[29] Chhabra SR, Shockley KR, Ward DE, Kelly RM. Regulation of endo-acting glycosyl hydrolases in the hyperthermophilic bacterium Thermotoga maritima grown on glucan- and mannan-based polysaccharides. Appl Environ Microbiol 2002; 68: 545-54.

[30] Luedeking R, Piret EL. A kinetic study of the lactic acid fermentation. Batch process at controlled pH. Biotechnol Bioeng 2000; 67: 636-44.

[31] Tevatia R, Demirel Y, Blum P. Kinetic modeling of photoautotropic growth and neutral lipid accumulation in terms of ammonium concentration in Chlamydomonas reinhardtii. Bioresour Technol 2012; 119: 419-24.

[32] Lakhal R, Auria R, Davidson S, Ollivier B, Dolla A, Hamdi M, et al. Effect of oxygen and redox potential on glucose fermentation in Thermotoga maritima under controlled physicochemical conditions. Internet J Microbiol 2010; 2010: 896510.

[33] Keasling JD, Benemann J, Pramanik J, Carrier TA, Jones KL, Van Dien SJ. A toolkit for metabolic engineering of bacteria. BioHydrogen. Springer; 1998. p. 87-97.

[34] Hallenbeck PC. Fundamentals of the fermentative production of hydrogen. Water Sci Technol 2005: 21-9. 
[35] Van Ginkel SW, Logan B. Increased biological hydrogen production with reduced organic loading. Water Res 2005; 39: 3819-26.

[36] Pirt SJ. The maintenance energy of bacteria in growing cultures. Proc R Soc Lond B Biol Sci 1965; 163: 224-31.

[37] de Vrije T, Mars AE, Budde MA, Lai MH, Dijkema C, de Waard P, et al. Glycolytic pathway and hydrogen yield studies of the extreme thermophile Caldicellulosiruptor saccharolyticus. Appl Microbiol Biotechnol 2007; 74: 1358-67.

[38] Eriksen N, Riis M, Holm N, Iversen N. H2 synthesis from pentoses and biomass in Thermotoga spp. Biotechnol Lett 2011; 33: 293-300.

[39] Liu S, Nichols N, Dien B, Cotta M. Metabolic engineering of a Lactobacillus plantarum double ldh knockout strain for enhanced ethanol production. J Ind Microbiol Biotechnol 2006; 33: 1-7.

[40] Levin DB, Pitt L, Love M. Biohydrogen production: prospects and limitations to practical application. Int J Hydrogen Energy 2004; 29: 173-85.

[41] Cha M, Chung D, Elkins JG, Guss AM, Westpheling J. Metabolic engineering of Caldicellulosiruptor bescii yields increased hydrogen production from lignocellulosic biomass. Biotechnol Biofuels 2013; 6: 85.

[42] Schicho RN, Ma K, Adams MW, Kelly RM. Bioenergetics of sulfur reduction in the hyperthermophilic archaeon Pyrococcus furiosus. J Bacteriol 1993; 175: 1823-30.

[43] Ravot G, Ollivier B, Fardeau ML, Patel BK, Andrews KT, Magot M, et al. $\mathrm{L}$-alanine production from glucose fermentation by hyperthermophilic members of the domains bacteria and Archaea: A remnant of an ancestral metabolism? Appl Environ Microbiol 1996; 62: 2657-9.

[44] Mu Y, Wang G, Yu HQ. Kinetic modeling of batch hydrogen production process by mixed anaerobic cultures. Bioresour Technol 2006; 97: 1302-7.

[45] Brethauer S, Wyman CE. Review: continuous hydrolysis and fermentation for cellulosic ethanol production. Bioresour Technol 2010; 101: 4862-74.

[46] Ren N-Q, Tang J, Liu B-F, Guo W-Q. Biological hydrogen production in continuous stirred tank reactor systems with suspended and attached microbial growth. Int J Hydrogen Energy 2010; 35: 2807-13.

[47] Chen CC, Lin CY, Chang JS. Kinetics of hydrogen production with continuous anaerobic cultures utilizing sucrose as the limiting substrate. Appl Microbiol Biotechnol 2001; 57: 56-64.

[48] Frascari D, Cappelletti M, Mendes J de S, Alberini A, Scimonelli F, Manfreda C, et al. A kinetic study of biohydrogen production from glucose, molasses and cheese whey by suspended and attached cells of Thermotoga neapolitana. Bioresour Technol 2013; 147: 553-61.

[49] d'Ippolito G, Dipasquale L, Vella FM, Romano I, Gambacorta A, Cutignano A, et al. Hydrogen metabolism in the extreme thermophile Thermotoga neapolitana. Int J Hydrogen Energy 2010; 35: 2290-5.

[50] Munro SA, Zinder SH, Walker LP. The fermentation stoichiometry of Thermotoga neapolitana and influence of temperature, oxygen, and $\mathrm{pH}$ on hydrogen production. Biotechnol Prog 2009; 25: 1035-42. 
[51] van Niel EWJ, Budde MAW, de Haas GG, van der Wal FJ, Claassen PAM, Stams AJM. Distinctive properties of high hydrogen producing extreme thermophiles, Caldicellulosiruptor saccharolyticus and Thermotoga elfii. Int J Hydrogen Energy 2002; 27: 1391-8.

[52] Jiang L, Long C, Wu X, Xu H, Shao Z, Long M. Optimization of thermophilic fermentative hydrogen production by the newly isolated Caloranaerobacter azorensis $\mathrm{H} 53214$ from deep-sea hydrothermal vent environment. Int J Hydrogen Energy 2014; 39: 14154-60.

[53] Kanai T, Imanaka H, Nakajima A, Uwamori K, Omori Y, Fukui T, et al. Continuous hydrogen production by the hyperthermophilic archaeon, Thermococcus kodakaraensis KOD1. J Biotechnol 2005; 116: 271-82.

[54] Ciranna A, Santala V, Karp M. Biohydrogen production in alkalithermophilic conditions: Thermobrachium celere as a case study. Bioresour Technol 2011; 102: 8714-22.

[55] Ciranna A, Pawar SS, Santala V, Karp M, van Niel EW. Assessment of metabolic flux distribution in the thermophilic hydrogen producer Caloramator celer as affected by external $\mathrm{pH}$ and hydrogen partial pressure. Microb Cell Factories 2014; 13: 48.

[56] Zeidan AA, van Niel EWJ. A quantitative analysis of hydrogen production efficiency of the extreme thermophile Caldicellulosiruptor owensensis OLT. Int J Hydrogen Energy 2010; 35: 1128-37.

[57] Soboh B, Linder D, Hedderich R. A multisubunit membrane-bound [NiFe] hydrogenase and an $\mathrm{NADH}$-dependent Fe-only hydrogenase in the fermenting bacterium Thermoanaerobacter tengcongensis. Microbiology 2004; 150: 2451-63.

[58] Jayasinghearachchi HS, Sarma PM, Lal B. Biological hydrogen production by extremely thermophilic novel bacterium Thermoanaerobacter mathranii A3N isolated from oil producing well. Int J Hydrogen Technol 2012; 37: 5569-78.

Figs. S1 \& S2 


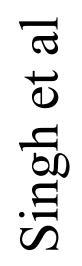

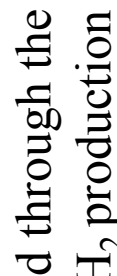

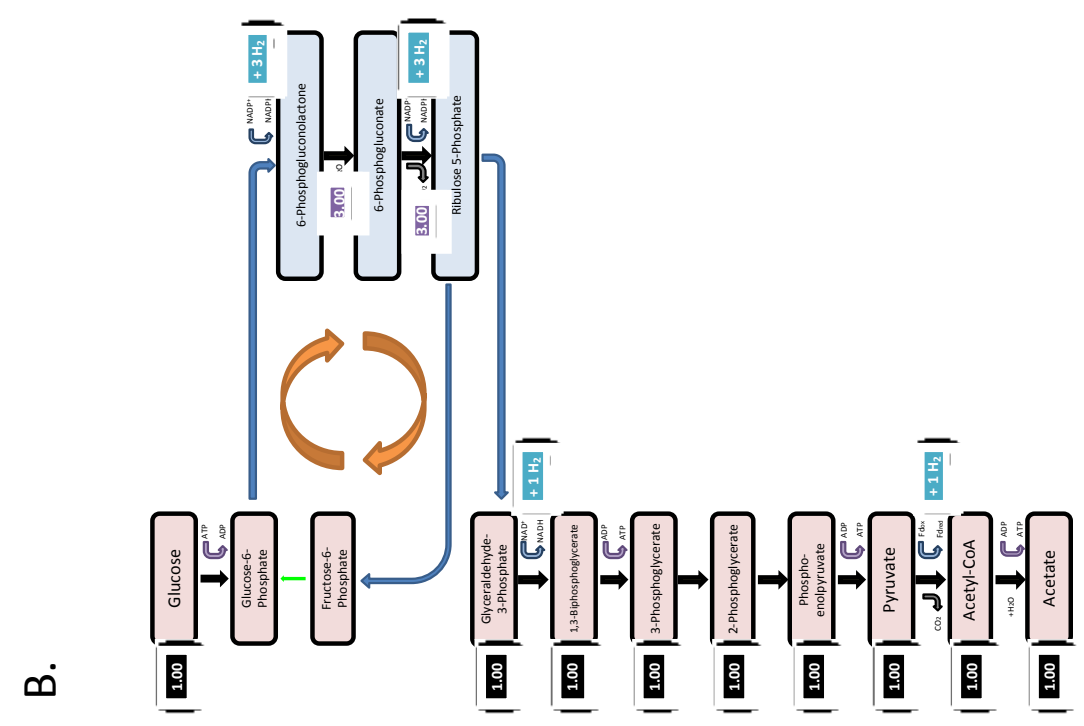

过

冢蒙

¿

용

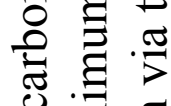

ฮ

글

.0

छี

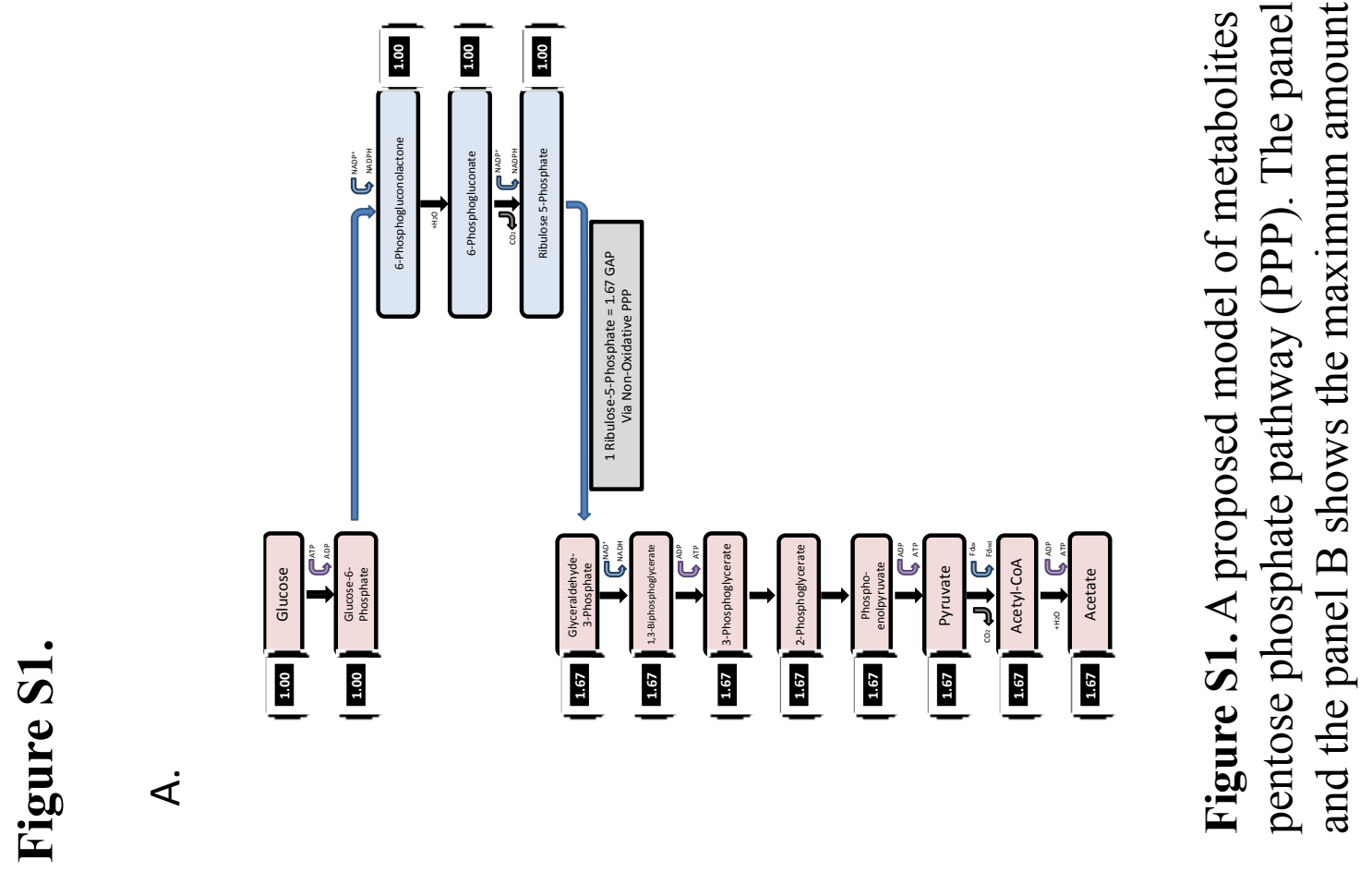


$\pi$
0
0
0
0
0

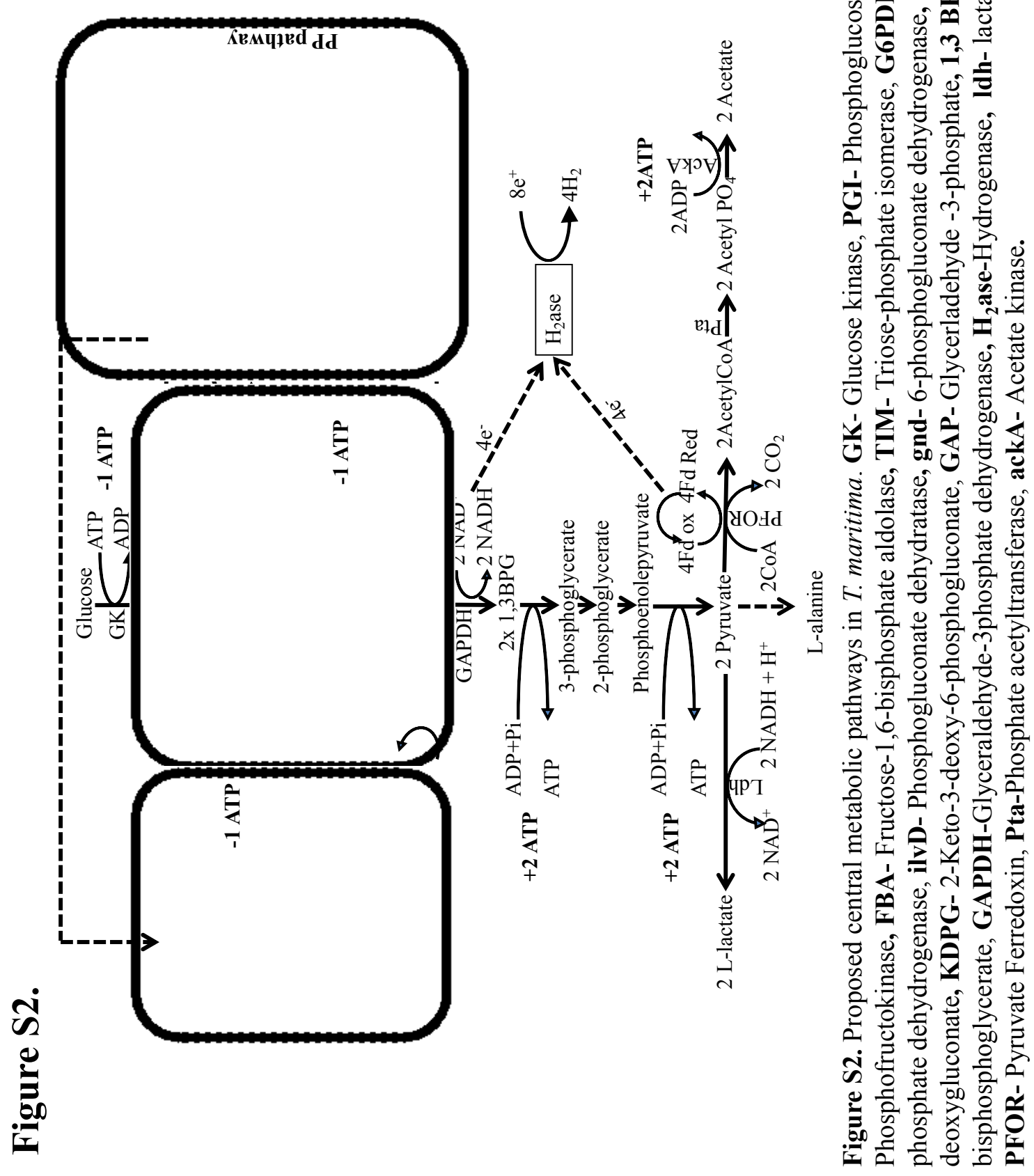

